\title{
A EVOLUÇÃO DO SISTEMA \\ DE PAGAMENTOS BRASILEIRO \\ UMA ABORDAGEM COMPARADA COM OS PAÍSES SELECIONADOS NO PERÍODO 1995-2003*
}

\author{
Divanildo Triches $^{* *}$
}

\section{Adriana Bertoldi}

RESUMO Este estudo tem o objetivo de analisar a evolução do sistema de pagamentos brasileiro, no período 1995-2003, e os efeitos sobre o mercado monetário decorrentes da sua reestruturação. Além disso, procura-se traçar um paralelo com os sistemas de pagamentos de alguns países selecionados. Os resultados indicam que a participação dos meios de pagamento no produto da economia está diretamente relacionada ao grau de desenvolvimento do sistema financeiro de cada país. Portanto, as economias desenvolvidas apresentaram participações mais expressivas dos meios de pagamento em relação aos seus produtos. Em abril de 2002, o Banco Central do Brasil implementou um novo sistema de pagamentos que seguiu a metodologia adotada internacionalmente, ou seja, sistema de liquidação pelo valor bruto em tempo real. Esse sistema conta com a transferência eletrônica disponível, com o propósito de efetuar liquidações de elevados valores também em tempo real. Os resultados indicaram que esse sistema ainda não trouxe efeitos relevantes sobre o comportamento dos meios de pagamento mais restritos. Contudo, há forte tendência de uma migração dos pagamentos realizados via instrumentos convencionais em direção a pagamentos processados por meios eletrônicos.

Palavras-chave: sistema financeiro; sistema de pagamentos; riscos sistêmicos; câmaras de compensação; agregados monetários; política monetária

Código JEL: E4, E42, E5, E58

\footnotetext{
* Artigo recebido em 19 de julho de 2005 e aprovado para publicação em 12 de maio de 2006.

** Doutor em Economia pela Universidade Federal do Rio Grande do Sul e professor na Universidade de Caxias do Sul, e-mail: dtriches@ucs.br

*** Bacharel em Economia pela Universidade de Caxias do Sul, e-mail: abertold@hotmail.com
} 


\title{
THE EVOLUTION OF THE BRAZILIAN SYSTEM OF PAYMENTS: A COMPARED APPROACH WITH THE SELECTED COUNTRIES IN THE PERIOD 1995-2003
}

\begin{abstract}
The study aims to analyze the evolution of the Brazilian system payments, in the period 1995-2003, and the effect on the monetary market due to its change. Moreover, a parallel with the systems of payment of some selected countries is done. The results indicate that the participation of the means of payment in the domestic product is directly related to the degree of development of the financial system. Therefore, the developed economies had presented higher participation of the means of payment in relation to its products. In April of 2002, a Brazilian Central Bank implemented a new system of payments which followed the methodology adopted internationally, or Real-time gross settlement systems. Furthermore, this system counts on the available electronic transference. It has a objective to transfer high values in real time as well. The results had pointed out that this system still did not bring relevant effects on the behavior of the means of more restricted payments. However, there is a strong trend of replacing conventional means of payments to electronic processed instruments.
\end{abstract}

Key words: financial system; system of payment; systemic risk; clearing; monetary aggregated; monetary policy 


\section{INTRODUÇÃO}

O sistema de pagamentos é um conjunto de normas, padrões e instrumentos que interligam e processam as transações entre os agentes econômicos não bancários, os bancos e o Banco Central. O montante de recursos transferidos por esses agentes pode ser dado por meio de cheques, cartões de crédito, transferências eletrônicas, documentos bancários de crédito e débito e papel-moeda. Contudo, as transações realizadas em papel-moeda têm apresentado uma redução significativa com o avanço e com o aumento da complexidade das atividades das economias.

Nesse aspecto, a sincronia da movimentação de recursos financeiros entre os agentes econômicos — portanto, a estabilidade do sistema financeiro — é uma questão que não pode ser facilmente controlada. Um sistema de pagamentos, na concepção de Brito (2002), deve contemplar principalmente a redução dos riscos sistêmicos inerentes ao seu funcionamento, já que as transferências de recursos envolvidas, qualquer que seja a razão, estão sujeitas à falta de cumprimento por parte de um ou mais integrantes do ciclo de pagamentos. Assim, os riscos de liquidação são destacadamente os mais relevantes. Em geral, eles são representados pelos riscos de crédito e pelos riscos de liquidez. Nesse sentido, a ausência de um mecanismo de proteção, dentro do sistema de pagamentos, implica perda de confiança e gera maior seletividade na concessão de crédito por parte do sistema financeiro, especialmente o interbancário. Esse processo, também designado risco sistêmico, se não adequadamente gerido, tem a capacidade de desestabilizar o sistema financeiro como um todo.

Com o intuito de reduzir a probabilidade de ocorrência de risco sistêmico no sistema financeiro brasileiro, o Banco Central do Brasil promoveu em abril de 2002 a reestruturação do sistema de pagamentos brasileiro. Nesse contexto, o estudo tem o objetivo de analisar a evolução dos meios de pagamentos no período 1995-2003 e os efeitos sobre o mercado monetário relativos à reestruturação do sistema de pagamentos brasileiro. Além disso, procura-se traçar um paralelo com os sistemas de pagamentos de alguns países selecionados.

Para tanto, o texto está organizado como segue. A seção 2 descreve, resumidamente, os aspectos teórico-conceituais do sistema financeiro e seu papel de prover a liquidez ao intermediar as transações econômicas e de 
transferir recursos ao longo do tempo. A seção 3 traz uma abordagem comparativa dos sistemas de pagamentos de países selecionados - Estados Unidos, Reino Unido, Japão, México e Argentina. A escolha desses países leva em consideração o nível de desenvolvimento do sistema financeiro e a posição geográfica das economias, distribuídas entre América do Norte, Europa, Ásia e América do Sul. A análise do funcionamento do sistema de pagamentos brasileiro utilizado até abril de 2002 e as razões que levaram o Banco Central a implantar um novo sistema, bem como os efeitos desse último sobre o mercado monetário, encontram-se na seção 4. Por fim, a seção 5 apresenta a conclusão e as considerações finais.

\section{ABORDAGEM TEÓRICA DO SISTEMA FINANCEIRO E SISTEMA DE PAGAMENTOS}

O sistema financeiro é composto por um conjunto de mercados que têm a característica básica de intermediar e prover liquidez às transações de compra e de venda dos ativos financeiros e ativos físicos. Esse sistema se apresenta em duas grandes subdivisões: (i) o subsistema bancário ou monetário, que tem o poder de criar liquidez a partir da emissão de moeda dada por meio da multiplicação dos depósitos, e (ii) o subsistema não monetário, que apenas realiza a intermediação dos recursos entre agentes econômicos superavitários e deficitários. ${ }^{1}$

Os agentes superavitários são aqueles nos quais a participação da renda auferida no seu respectivo orçamento é superior aos gastos realizados, ou ainda, são os que preferem um menor nível de utilidade em termos de consumo no tempo presente para ter um nível mais elevado no futuro. Assim sendo, essa classe de indivíduos constitui-se em geradores líquidos de poupanças. Os agentes deficitários comportam-se no sentido oposto, isto é, seus dispêndios são maiores em termos proporcionais às suas rendas auferidas; por conseguinte, são caracterizados como tomadores líquidos de recursos.

Obviamente, toda atividade de intermediação financeira é promovida por um conjunto de atores designados por intermediários financeiros, que podem ser bancários ou não bancários. Eles viabilizam o atendimento das necessidades financeiras de curto, médio e longo prazos, requeridas pelos agentes carentes, e as aplicações das disponibilidades dos agentes com excedentes orçamentários. Assim, essa intermediação ocorre pelo fato de que os 
custos de transação evolvidos tendem a ser muito elevados na negociação direta entre os agentes. Desse modo, os intermediários financeiros tendem a apresentar um altíssimo nível de especialização e sofisticação na avaliação e seleção dos tomadores de recursos, objetivando tornar os riscos associados a essas operações os menores possíveis. Nessa categoria, encontram-se bancos comercias e múltiplos, bancos de investimentos, associações de poupança e empréstimo, fundos institucionais como as companhias de seguro, fundos de pensão, fundos de ações e fundos mútuos. ${ }^{2}$

Os instrumentos que integram a intermediação financeira constituemse em muitas alternativas de investimento disponíveis nas economias. Essas alternativas são apresentadas basicamente em duas formas: (a) ativos reais ou físicos, como imóveis, terrenos, metais preciosos, obras de arte, ativos estrangeiros etc. e (b) ativos financeiros ou títulos, os quais representam um direito contratual de receber pagamentos futuros nas condições (se cumpridas) previamente acordadas. Sob essa designação encontra-se um elevado número de opções disponíveis como títulos de renda fixa, possivelmente os mais usuais, representados pelos depósitos a prazo feitos nas instituições bancárias. Além disso, há ainda os títulos de renda variável, geralmente constituídos pelas ações emitidas pelas corporações.

O mercado financeiro, como outro mercado qualquer, funciona eficientemente quando os participantes integram um sistema de pagamentos eficiente. Um sistema de pagamentos é entendido como um conjunto de normas, padrões e instrumentos que promove e dá liquidez aos recursos transferidos entre instituições financeiras e demais agentes econômicos. Esse sistema, na concepção de Brito (2002), deve contemplar principalmente a redução dos riscos inerentes ao seu funcionamento. Por exemplo, os riscos associados à liquidação das operações estão sempre presentes em todas as transações. Tais riscos referem-se aos chamados risco de crédito e risco de liquidez. O primeiro caracteriza-se pela possibilidade de uma das contrapartes de uma transação não cumprir suas obrigações no prazo estabelecido ou posterior. ${ }^{3}$ O segundo resulta da falta de cumprimento de uma obrigação por um dos participantes de uma transação no prazo estabelecido, mas que poderá vir a ser cumprida no futuro. A rede na qual o sistema de pagamentos, segundo Lima (2002), opera é um forte potencial de transmissão de distúrbios e, portanto, uma possibilidade constante de geração de risco sistêmico. 
Além disso, ao longo dos anos 80 e 90, tem-se registrado um aumento significativo nos fluxos globais de capitais, resultado de uma progressiva liberalização e inovação nos instrumentos financeiros. Desde então, a maioria dos bancos centrais do grupo de dez países (G-10) integrantes do Comitê de Sistemas de Pagamentos e de Liquidações (CSPL) — órgão vinculado ao Banco Internacional de Compensação (BIS) — tem feito consideráveis esforços no sentido de fortalecer e solidificar o funcionamento dos sistemas de pagamentos. ${ }^{4}$ Nesse sentido, foram realizados estudos para identificar diferentes métodos de liquidação de transações e seus respectivos riscos. O quadro 1 apresenta uma classificação dos sistemas de pagamentos caracterizados por sistemas de transferências interbancárias de fundos ou recursos de grandes valores. Esses sistemas podem ser subdividos em sistemas de liquidação pelo valor líquido e sistemas de liquidação pelo valor bruto. Outra forma de subdividir esses sistemas é de acordo com o horário e a freqüência de liquidação das transferências, ou seja, liquidação em horário específico — nesse caso, a liquidação é diferida — e liquidação em tempo real, também conhecida como liquidação contínua.

Uma terceira forma de tratar os sistemas de pagamentos é de acordo com quem os opera, ou seja, bancos centrais e setores privados. Os sistemas de transferências de fundos de grandes valores geridos pelos bancos centrais ou operados pelas suas entidades afiliadas têm como responsável final pela liquidação da transação o próprio Banco Central. Esses modelos de pagamentos são do tipo liquidação pelo valor bruto em tempo real (LBTR). Além disso, nos sistemas de transferências de fundos de grandes valores geridos ou pertencentes ao setor privado e representados pelo sistema de liquidação

Quadro 1: Classificação dos sistemas de transferências de recursos de grandes valores*

\begin{tabular}{ccc}
\hline Características da liquidação & Pelo valor bruto & Pelo valor líquido \\
\hline $\begin{array}{c}\text { Horário específico } \\
\text { (diferida) }\end{array}$ & $\begin{array}{c}\text { Liquidação pelo valor bruto } \\
\text { em horário específico }\end{array}$ & $\begin{array}{c}\text { Liquidação diferida pelo valor } \\
\text { líquido (LDL) }\end{array}$ \\
\hline $\begin{array}{c}\text { Contínua } \\
\text { (em tempo real) }\end{array}$ & $\begin{array}{c}\text { Liquidação pelo valor bruto } \\
\text { em tempo real (LBTR) }\end{array}$ & Não aplicável** \\
& & \\
\hline
\end{tabular}

Fonte: Andima (2002).

* Esses sistemas são definidos por Large-Value Funds Transfer System (LVTS). (1) Deferred Gross Settlement (DGS). (2) Deferred Net Settlement (DNS). (3) Real Time Gross Settlement (RTGS).

** A apuração dos saldos líquidos envolve a acumulação de certo número de transações, de forma que os créditos possam ser balanceados com os débitos, o que é incompatível com a liquidação contínua. 
diferida pelo valor líquido (LDL), também compete ao Banco Central efetuar as liquidações.

No sistema de compensação pelo valor líquido (LDL), a liquidação das transferências de fundos ocorre no período de tempo predeterminado e pelo valor líquido de cada participante. A posição líquida, por sua vez, é calculada pela soma dos valores das transferências recebidas até uma determinada hora, deduzida da soma dos valores das transferências enviadas. As instruções de pagamento são liquidadas somente ao final do período, pelo valor líquido total apurado. A principal vantagem de sistemas LDL é a pequena exigência de reservas bancárias, pois a compensação multilateral dos valores entre os participantes reduz o volume de recursos a serem transferidos. Por outro lado, a defasagem de tempo na liquidação cria concessão implícita de crédito do banco recebedor para o banco pagador, o que expõe os participantes ao risco de crédito.

Os sistemas de liquidação pelo valor bruto e em tempo real (LBTR) são aqueles que executam a liquidação definitiva de transferências interbancárias de fundos em bases contínuas e instantâneas, transação a transação. São sistemas tipicamente eletrônicos nos quais se transmitem e se processam informações em tempo real. Tais sistemas contribuem para limitar ou mesmo eliminar os riscos sistêmicos de pagamentos; todavia, como os valores envolvidos são elevados, requerem maiores níveis de reservas bancárias. Por fim, os sistemas LBTR podem contribuir também para a redução dos riscos de pagamento nas transações com títulos e de câmbio, mediante a adoção de mecanismos de entrega contra pagamento (ECP) ou de mecanismos de pagamento contra pagamento (PCP). ${ }^{5}$

\section{SISTEMA DE PAGAMENTOS EM PAÍSES SELECIONADOS}

O desenvolvimento de sistemas de pagamentos procura essencialmente reduzir os riscos envolvidos nas transações e evitar o colapso do sistema como um todo. Para tanto, analisa-se o sistema de pagamentos de alguns países desenvolvidos - EUA, Japão e Reino Unido - e duas economias da América Latina, a argentina e a mexicana.

Os Estados Unidos, o Japão e o Reino Unido, bem como a grande maioria dos demais países integrantes do Grupo dos Dez (G-10), introduziram nos seus sistemas de pagamentos a transferência de fundos de grandes valores 
(LBTR), no decorrer dos anos 80 e 90. A adoção desse sistema é uma resposta à necessidade de uma eficaz administração de riscos nos sistemas de pagamentos. O primeiro sistema LBTR automático foi desenvolvido pelos Estados Unidos e é conhecido como Fedwire (Fedwire Funds Transfer Service). A tabela 1 mostra que a sua versão moderna foi implantada ainda na década de 1970. Ela é baseada numa rede computadorizada de telecomunicações e processamento eletrônico de alta velocidade. A partir desse sistema, o valor médio das transações cresceu de US\$ 2,9 milhões para US\$ 6,1 milhões em relação ao sistema anterior, e o total de transações como proporção do produto daquele país subiu de $30,7 \%$ para $42,7 \%$.

O sistema LBTR também está presente no Reino Unido, representado pela Chaps que passou a vigorar a partir de 1984. Esse modelo de pagamentos pertence a uma rede de instituições financeiras e ao Banco Central. Nesse sistema, todos os participantes estão interconectados ao sistema interno de contabilidade em tempo real com o Banco Central. É permitido acesso direto a todos os bancos, todas as instituições de crédito, instituições depositárias, entre outros, desde que os integrantes possuam solidez financeira e conhecimentos técnicos aplicados a cada sistema, além de contas mantidas no Banco Central. Assim, para iniciar a transferência de fundos, o banco pagador emite uma mensagem de pagamento, que é em seguida roteada para o Banco Central e essa, por sua vez, é enviada para o banco recebedor, quando ocorre o processamento e a liquidação da transferência. Os dispositivos

\begin{tabular}{|c|c|c|c|c|c|}
\hline País & Sistema & Tipo & $\begin{array}{c}\text { Data } \\
\text { de implantação }\end{array}$ & $\begin{array}{l}\text { Valor médio } \\
\text { das transações } \\
\text { (US\$ milhões) }\end{array}$ & $\begin{array}{c}\text { Transações/ } \\
\text { PIB } \\
(\%)\end{array}$ \\
\hline \multirow[t]{2}{*}{ Estados Unidos } & Chips & LDL & 1970 & 6,1 & 42,7 \\
\hline & Fedwire & LBTR & 1988 & 2,9 & 30,7 \\
\hline \multirow[t]{2}{*}{ Japão } & Boj-net & $\mathrm{LDL}+\mathrm{LBTR}$ & 1988 & 112,9 & 85,0 \\
\hline & Feycs & LDL & 1989 & 9,2 & 16,0 \\
\hline Reino Unido & Chaps(*) & LBTR & 1984 & 3,4 & 38,1 \\
\hline
\end{tabular}

Fonte: BIS (1997).

* Referem-se a versões anteriores dos sistemas, que mudaram de liquidação pelo valor líquido para LBTR em abril de 1996. Nota: Chips (Clearing House Interbank Payments System), Câmera de Compensação do Sistema de Pagamentos Interbancário; Fedwire (Fedwire Funds Transfer Service), Serviços de Transferências de Fundos; Boj-net (Bank of Japan Financial Network System), Sistema de Rede Financeira do Banco do Japão; Feycs (Foreign Exchange Yen Clearing System), Sistema de Compensação de Câmbio do lene; Chaps (Clearing House Automated Payment System), Câmera de Compensação do Sistema de Pagamentos Automatizado; LBTR, Liquidação pelo Valor Bruto em Tempo Real; e LDL, Liquidação Diferida pelo Valor Líquido. 
para roteamento de mensagens de pagamento são baseados nas estruturas de fluxo de mensagens, que podem ser nos formatos em $\mathrm{V}$ e em $\mathrm{L}$, conforme descreve a figura $1 .^{6}$

No caso particular do sistema Chaps, a estrutura de comunicação é no formato em L. A mensagem de pagamento enviada pelo banco emitente é mantida numa porta de comunicação vinculada ao sistema de processamento interno do banco pagador. Um subconjunto de informações, contido na solicitação de liquidação, é remetido para o Banco Central. Havendo fundos suficientes por parte do banco pagador ou emissor, a liquidação é completada. O Banco Central retorna uma mensagem de confirmação e, desse modo, o pagamento é liberado e, portanto, remetido ao banco recebedor. Contudo, a estrutura de fluxo de mensagens no formato em $\mathrm{V}$ é encontrada no sistema de pagamentos japonês Boj-net e no sistema dos EUA Fedwire. Sob essa configuração, a mensagem completa de pagamento é inicialmente transmitida para o Banco Central e imediatamente remetida ao banco recebedor, após a liquidação da transferência dos recursos.

No que se refere à estrutura das contas no Banco Central, há diferenças nos sistemas LBTR entre os Estados Unidos, o Japão e o Reino Unido. Os

Figura 1: Estruturas de fluxo de mensagens nos sistemas de pagamentos nos formatos em $V$ e em $L$

No formato em V

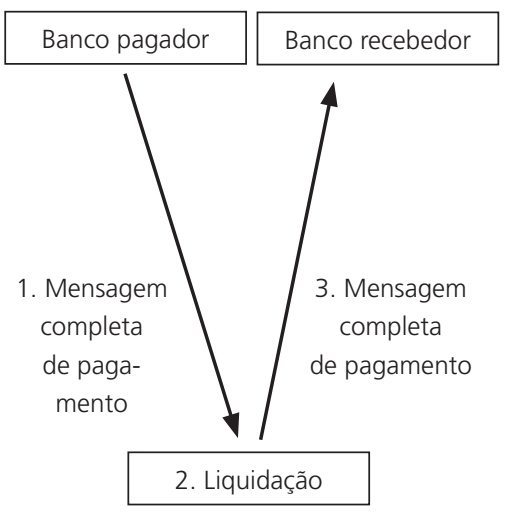

Banco Central
No formato em L

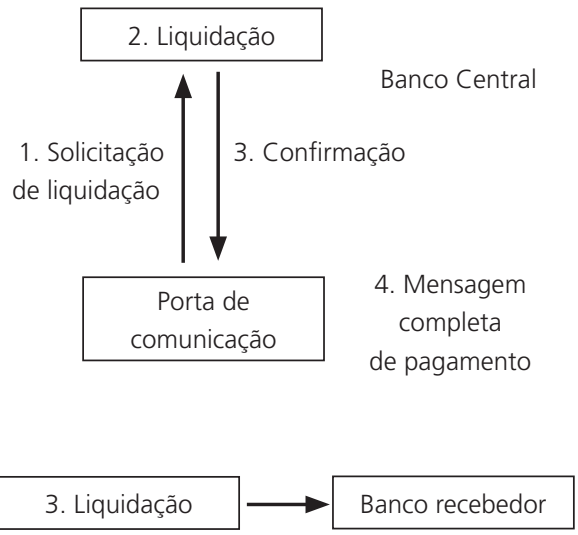


modelos de pagamentos podem ser divididos em dois grupos: (a) sistemas sem e (b) sistemas com fornecimento de crédito intradia - ao longo do expediente diário — pelo Banco Central. No Boj-net, o Banco Central japonês não fornece crédito intradia. As ordens de transferência descobertas, e.g., são rejeitadas e devolvidas ao banco remetente. No entanto, o papel de oferecer recursos para cobrir a necessidade de liquidez nos intervalos de liquidação LDL no sistema Boj-net é desempenhado pelo mercado interbancário intradia. Aliás, o mercado monetário intradia japonês é o mais desenvolvido dentre os países do Grupo dos Dez. Já nos sistemas LBTR dos EUA e do Reino Unido, os bancos centrais oferecem e permitem esse tipo de transferência. Por exemplo, se uma instituição incorrer em saque a descoberto, o Fedwire cobra um encargo baseado na média diária de saques, mas o valor a descoberto diário possui um limite predeterminado. O sistema Chaps, por sua vez, não permite saque a descoberto, mas o Banco Central oferece, em substituição, liquidez intradia, mediante contratos de recompra intradia.

Ressalta-se ainda que, independentemente da disponibilidade de instrumentos de crédito intradia, os bancos centrais oferecem alguns instrumentos de financiamento. As regras operacionais dos sistemas de pagamentos requerem que um banco somente emita ordens de liquidação se houver fundos suficientes retidos em sua conta no Banco Central. Entretanto, se um banco emite, de forma equivocada, uma ordem com insuficiência de fundos, a ordem será enfileirada centralmente e, portanto, bloqueada. ${ }^{7}$

No que concerne ainda à análise dos sistemas de pagamentos dos países selecionados, nota-se que o sistema financeiro das economias mexicana e argentina tende a ser relativamente vulnerável. Tal fato decorre por conta da fragilidade das características específicas nas quais estão estruturados os sistemas de pagamentos. Por exemplo, a partir da década de 1980, o México implementou um conjunto de reformas no sistema financeiro determinantes para sua inserção no contexto internacional. Em 1994, o Banco do México modificou seu sistema de pagamentos adotando o LBTR, com o objetivo de substituir os cheques de altos valores e diminuir os riscos de crédito ao público. Na realidade, o LBTR comporta o Sistema de Pagamentos Eletrônicos de Uso Ampliado (SPEUA), ao qual apenas os bancos têm acesso para realizar pagamentos de altos valores com liquidação ao longo de um dia, e o Sistema Interativo para Depósitos de Valores (SIDV), utilizado na 
liquidação das transações de valores por meio do mecanismo de entrega contra pagamento (ECP). O Banco do México tem a propriedade e opera os dois sistemas, os quais exigem que as transações sejam liquidadas mediante a existência de saldo disponível nas contas dos participantes envolvidos.

A estrutura de pagamentos, no México, também comporta sistemas LDL, em que o Centro de Compensação Bancária presta serviços de compensação de cheques com cobertura em todo o país e realiza a compensação diferida de pagamentos eletrônicos. O Sistema de Câmaras (Sicam) operado pelo Banco do México compensa os pagamentos processados pela Cecoban sempre na manhã seguinte ao movimento ocorrido, por meio de confronto de informações ainda de forma manual.

O Banco Central da República Argentina (BCRA), por sua vez, redefiniu os sistemas de pagamentos no país em 1996, passando a introduzir um sistema LBTR como o Meio Eletrônico de Pagamentos. Além disso, a compensação das transações monetárias de baixos e de altos valores passou a ser realizada por câmaras eletrônicas de compensação (CEC), administradas pelo setor privado. ${ }^{8}$ Essas câmaras têm a função de prestar serviços de compensação de instrumentos de pagamentos às instituições e entidades financeiras associadas, além das condições de segurança, infra-estrutura de telecomunicações e planos de contingência.

O sistema Meio Eletrônico de Pagamentos permite que as instituições autorizadas realizem transferências em tempo real por meio de suas contas correntes no Banco Central. Isso se dá num ciclo operacional prolongado, cuja finalidade é disponibilizar aos usuários informações em tempo real acerca de seus saldos. A segurança nas transações é obtida com procedimentos rigorosos a serem seguidos pelas instituições ao enviar os pagamentos para o sistema. Para isso, são definidos níveis de operações específicos como o carregamento de operações, autorizações e consultas. Assim, o operador de carregamento inicia as operações, que são verificadas e autorizadas. Essa autorização confirma o débito na conta da instituição solicitante e o crédito na conta da instituição beneficiária. A partir desse estágio, as transações serão irrevogáveis. O Meio Eletrônico de Pagamentos não possui mecanismos de controle nem facilidades de liquidez intradia.

Desde 1997, existem duas Câmaras Eletrônicas de Compensação privadas de baixos valores ou de valores de terceiros: a ACHSA e a Compensa- 
dora Eletrônica S.A. (Coelsa). Ambas são autorizadas pelo Banco Central argentino a compensarem eletronicamente cheques e outros documentos, débitos diretos e transferências de baixos valores. Essas câmaras estão interligadas para intercambiarem as transações entre as instituições financeiras afiliadas. As Câmaras Eletrônicas de Compensação de altos valores ou câmaras de compensação de valores de instituições financeiras também são representadas por duas câmaras: (i) a Interbanking, que começou a operar em 1998, prestando serviços de liquidação LDL para os bancos e serviços de transferência eletrônica de fundos para empresas, e (ii) a Provincaje, que entrou em funcionamento em 2000, fornecendo os mesmos serviços para o interbancário. ${ }^{9}$

Quanto à relação entre os sistemas de pagamentos e o desempenho das economias, observa-se, inicialmente, que o crescimento do produto doméstico dos países, em particular o dos mercados emergentes, tende a estar associado à trajetória da economia mundial. Esta, por sua vez, é fortemente vinculada ao comportamento do produto dos EUA. Por exemplo, em 2001, a redução do nível de atividade norte-americana teve influência negativa sobre os demais países. Dessa forma, a condução da política monetária pelos bancos centrais das nações mais desenvolvidas tem levado em conta esse ritmo mais lento nas atividades. Para efeito ilustrativo, o Banco Central do Reino Unido adotou uma política monetária de controle direto sobre as mudanças da taxa de juros e das metas de inflação. Esse objetivo foi claro no sentido de isolar a economia doméstica dos efeitos da desaceleração da economia mundial. Tal fato pode ser comprovado pelo melhor desempenho entre as economias analisadas, como mostra a tabela 2. A taxa de crescimento do produto doméstico manteve-se acima de $2 \%$, caindo para $1,7 \%$ em 2002. Observa-se ainda que a participação do M4 sobre o PIB do Reino Unido teve uma forte elevação, passando de 87,3\% em 1995 para 96,8\% em 2002, enquanto a participação máxima do agregado monetário mais restrito foi de $3,7 \%$ do produto.

A economia dos EUA também tem revelado um bom desempenho no período 1995-2002, salvo em 2001, quando o crescimento não superou $0,5 \%$, conforme pode-se notar ainda na tabela 2 . Além disso, as razões entre os agregados monetários e o produto total daquela economia têm sido divergentes. A participação do conceito M1 apresentou uma trajetória decli- 
Tabela 2: Evolução dos meios de pagamentos nos países selecionados no período 1995-2002

\begin{tabular}{lcrrrrrrrr}
\hline Indicadores/Anos & 1995 & 1996 & 1997 & 1998 & 1999 & 2000 & 2001 & 2002 & \\
\hline \multirow{4}{*}{ Cresc. } & Argentina & $-2,8$ & 5,5 & 8,1 & 3,9 & $-3,4$ & $-0,8$ & $-4,4$ & $-11,0$ \\
PIB (\%) & México & $-6,2$ & 5,2 & 6,8 & 4,9 & 3,7 & 6,6 & $-0,3$ & 0,9 \\
& EUA & 2,7 & 3,7 & 4,5 & 4,2 & 4,4 & 4,1 & 0,5 & 2,2 \\
& R.U. & 2,9 & 2,7 & 3,3 & 3,1 & 2,8 & 3,3 & 2,1 & 1,7 \\
& Japão & 1,6 & 3,5 & 1,8 & $-1,2$ & 0,2 & 1,5 & 0,4 & $-0,3$ \\
\hline \multirow{2}{*}{ M1 } & Argentina & 7,1 & 6,9 & 7,2 & 7,1 & 7,6 & 6,9 & 5,8 & 27,7 \\
\% do PIB & México & 9,3 & 8,0 & 10,2 & 10,0 & 10,6 & 10,2 & 11,6 & 12,4 \\
& EUA & 15,5 & 14,1 & 13,1 & 12,7 & 12,2 & 11,3 & 11,9 & 11,8 \\
& R.U.* & 3,4 & 3,4 & 3,4 & 3,4 & 3,6 & 3,6 & 3,7 & 3,7 \\
\hline \multirow{2}{*}{ M2 } & Japão & 34,4 & 36,6 & 38,9 & 41,3 & 46,7 & 48,1 & 55,7 & 69,4 \\
\hline do PIB & Argentina & 16,5 & 15,5 & 18,9 & 21,3 & 23,5 & 24,7 & 21,0 & 58,0 \\
& México & 40,9 & 39,4 & 41,2 & 43,4 & 44,2 & 43,0 & 47,5 & 50,1 \\
& EUA & 49,4 & 49,0 & 48,7 & 50,1 & 50,3 & 50,5 & 54,3 & 55,9 \\
& R.U. & 87,3 & 90,2 & 89,1 & 92,3 & 90,6 & 93,4 & 94,9 & 96,8 \\
& Japão & 75,6 & 72,9 & 71,6 & 75,0 & 74,8 & 74,3 & 71,7 & 72,9 \\
\hline
\end{tabular}

Fonte: Banco Mundial (2003) e Fundo Monetário Internacional (2003).

* Refere-se ao agregado M0 em substituição a M1 e M4, em vez de M2.

nante, passando de 15,5\% em 1995 para 11,8\% sete anos depois. Diferentemente, o conceito M2 cresceu de 49,4\% para 55,9\%, respectivamente. Esse fato mostra uma redução dos meios de pagamentos para realizar transações econômicas, o que decorre do surgimento de sistemas de pagamentos mais eficientes.

A economia japonesa, dentre os países desenvolvidos analisados, tem apresentado o pior desempenho. Ela foi seriamente afetada pela crise dos países asiáticos, teve um leve crescimento de 1,8\% em 1997 e decresceu em 1,2\% no ano seguinte. Além disso, ao longo do período 1999-2002, as taxas registradas também foram pouco expressivas, como ainda revela a tabela 2. O fato que chama atenção refere-se às participações dos agregados monetários em relação ao produto total. Por exemplo, o conceito mais restrito representava mais de 1/3 em 1995 e passou para mais de 2/3 em 2002. Já a representatividade do $\mathrm{M} 2$ sobre o produto doméstico tem girado na faixa de 75,6\% a 71,6\% no respectivo período. Assim, o avanço do processo de reestruturação do sistema bancário japonês, sobrecarregado pelo grande volume de empréstimos de pouca qualidade, não foi suficiente para restabelecer as condições de liquidez necessárias para promover o dinamismo dos principais setores da economia. 
No México, o fortalecimento da regulação e supervisão do sistema de pagamentos e de diversas reformas nas leis bancárias contribuiu para aumentar a solvência do sistema financeiro. Ao longo dos anos 1997-2000, a política monetária foi utilizada de forma restritiva para impedir uma emissão de moeda que pudesse potencializar ataques especulativos. Desse modo, a participação do M1 em relação ao produto total manteve-se relativamente estável, ficando em torno de 10\% naquele período, como ilustra a tabela 2. Já o agregado monetário um pouco mais amplo, M2, na proporção do produto, teve uma oscilação maior, ou seja, em 1995 ele representava $40,9 \%$ e cresceu para 50,1\% em 2002. Claramente após a crise verificada na economia mexicana em 1994-1995, as taxas de crescimento do produto doméstico situaram-se no intervalo de aproximadamente 4,0\% a 7,0\%. O desempenho da economia voltou a ser fraco, com taxa negativa e abaixo de $1,0 \%$ em 2001 e 2002, respectivamente.

O setor bancário argentino tem apresentado mudanças relevantes a partir dos anos 90. A consolidação do sistema e a entrada de bancos estrangeiros têm ampliado a oferta de serviços e aumentado a confiança do público. Como conseqüência, houve uma elevação na quantidade total de depósitos, embora parte da população ainda não tenha acesso aos serviços bancários. A quantidade total da moeda argentina em circulação e os depósitos à vista mantiveram-se constantes desde 1995 , oscilando na faixa de 5,8\% a 7,6\% do PIB. Entretanto, essa relação saltou para 27,7\% em 2002, o que pode ser justificado pela desvalorização da moeda e pela redução do produto argentino. Aliás, a economia argentina decresceu continuamente a partir de 1999, registrando uma queda espetacular no seu produto doméstico — ou seja, de $11,9 \%$ - em 2002.

Em síntese, a análise dos sistemas de pagamentos e do comportamento dos meios de pagamento em relação ao PIB dos países selecionados permite afirmar que as economias desenvolvidas apresentam sistemas financeiros e sistemas de pagamentos relativamente mais avançados, além de maiores participações percentuais dos meios de pagamento sobre o PIB, que as economias em desenvolvimento. 


\section{EVOLUÇÃO DO SISTEMA DE PAGAMENTOS BRASILEIRO}

O sistema de pagamentos consiste num conjunto de instrumentos, procedimentos e regras que possibilitam a transferência de recursos financeiros entre agentes não bancários, bancos e o Banco Central, como foi previamente discutido. Além disso, os sistemas de pagamentos têm o papel de instrumentalizar a política monetária. No Brasil, o sistema de pagamentos anterior a abril de 2002 — quando entrou em vigor o novo sistema — era composto, como esquematizado na figura 2, por quatro câmaras de compensação:

(i) Selic (Sistema Especial de Liquidação e Custódia): realizava as transações primárias e secundárias, envolvendo títulos públicos federais, alguns títulos estaduais e municipais, e as transações de compra ou de venda de CDI (Certificado de Depósito Interbancário). A liquidação financeira era defasada pelo valor líquido multilateral (LDL).

(ii) Cetip (Central de Custódia e de Liquidação Financeira de Títulos Privados): efetuava o controle das negociações de títulos privados e alguns títulos públicos. A liquidação também era defasada e processada pelo valor líquido multilateral e a transferência da reserva bancária para a conta cor-

Figura 2: Sistema de pagamentos brasileiro antes da reestruturação em abril de 2002

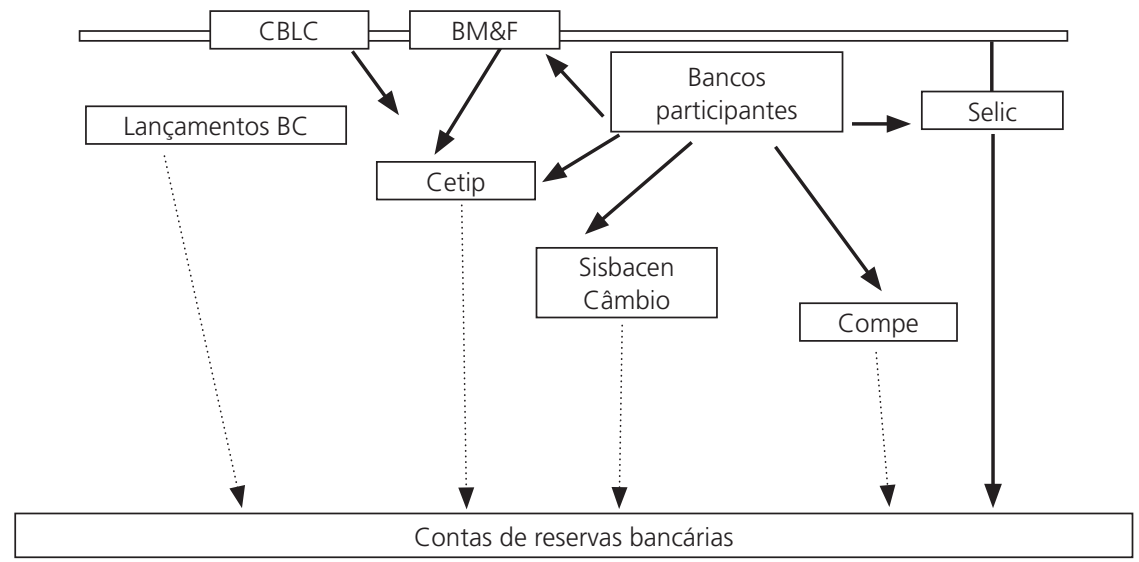

Fonte: Andima (2002: 18).

Nota: BC, Banco Central do Brasil; BM\&F, Bolsa de Mercadoria e Futuros; Cetip, Central de Custódia e de Liquidação Financeira de Títulos Privados; Compe, Serviço de Compensação de Cheques e Outros Papéis; CBLC, Companhia Brasileira de Liquidação e Custódia; Selic, Sistema Especial de Liquidação e Custódia; Sisbacen, Sistema do Banco Central. 
rente da instituição financeira se dava um dia após a contratação $(\mathrm{D}+1)$. Essa câmara também se encarregava das mensagens de liquidação financeira das bolsas de valores e da Bolsa de Mercadorias e Futuros (BM\&F) para movimentação das contas de reservas bancárias do Banco Central.

(iii) Câmbio (Sistema de Câmbio): realiza transações interbancárias em moeda estrangeira. A liquidação da moeda nacional era defasada e processada pelo valor bruto (uma a uma) geralmente dois dias após a negociação. O registro da liquidação em moeda nacional era feito no Sistema do Banco Central ou Sisbacen, o qual movimentava as contas de reservas bancárias dos bancos envolvidos. Na realidade, esse sistema não consistia numa câmara de compensação tradicional. ${ }^{10}$

(iv) Compe (Serviço de Compensação de Cheques e Outros Papéis): tinha por responsabilidade a compensação de cheques e outros papéis, como documentos de ordem de crédito (DOC), bloquetos de cobrança, cartões de crédito etc. A liquidação era defasada e processada pelo valor multilateral, acontecendo no dia seguinte ao da compensação, no caso de cheques de valor igual ou superior a um determinado limite. ${ }^{11}$

Esse sistema de pagamentos apresentava-se bastante vulnerável, uma vez que a maior parte das liquidações ocorria por meio da Compe, que era desprovida de instrumentos de controle de riscos. O Banco Central passava a assumir toda a responsabilidade dentro da cadeia de pagamentos. Portanto, ele ficava suscetível a riscos sistêmicos, em caso da falta de cumprimento da liquidação por um ou mais integrantes do sistema. Além do mais, as câmaras de compensação não possuíam mecanismos de proteção que assegurassem a liquidação de todas as operações, na hipótese de falência de um participante. Havia também um elevado intervalo de tempo para a liquidação nas bolsas, reduzindo sua competitividade internacional na atratividade de investidores externos.

Com a finalidade de tornar o sistema de pagamentos brasileiro mais seguro e adequado à realidade da economia brasileira, o Banco Central adotou um novo sistema que entrou em operação em 2002. A partir da introdução das novas regras, os saldos negativos na conta de reservas bancárias não foram mais permitidos em qualquer momento. Esse fato implicou duas mudanças a salientar: (i) os sistemas de compensação e liquidação, administrados pelo BC, passaram a efetuar a liquidação de operações via siste- 
Figura 3: Configuração do novo sistema de pagamentos brasileiro implantado em abril de 2002

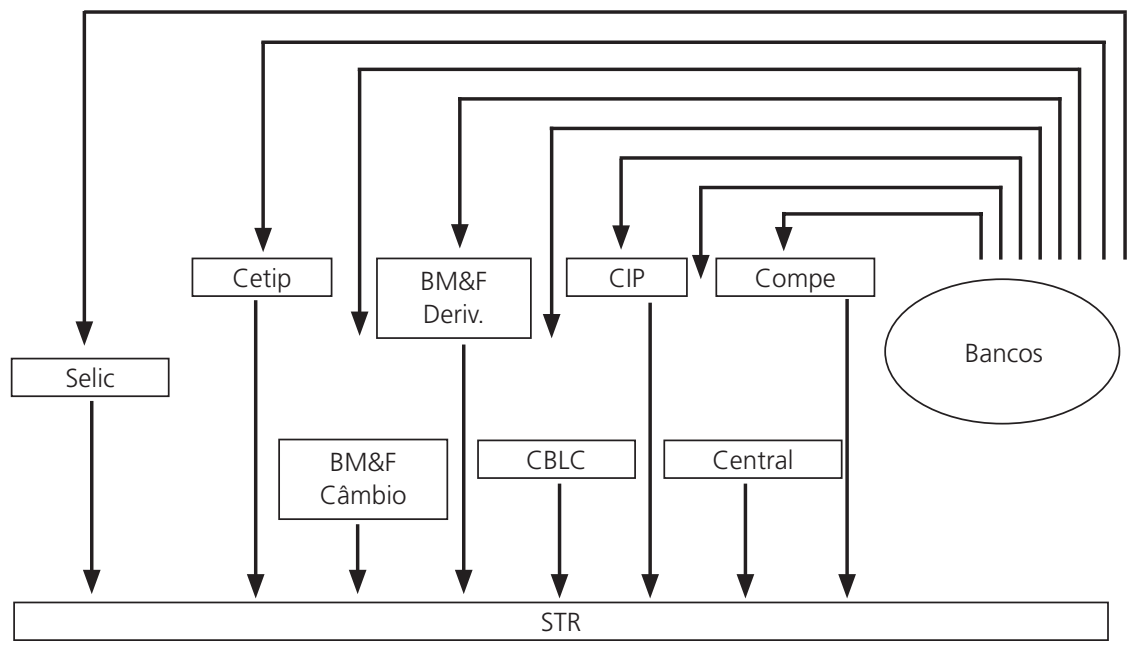

Contas de reservas bancárias

Fonte: Andima (2002: 18).

Nota: BM\&F, Bolsa de Mercadoria e Futuros; Central, Central Clearing de Compensação e Liquidação S.A.; Cetip, Central de Custódia e de Liquidação Financeira de Títulos Privados; CIP, Câmara Interbancária de Pagamentos; Compe, Serviço de Compensação de Cheques e Outros Papéis; CBLC, Companhia Brasileira de Liquidação e Custódia; Selic, Sistema Especial de Liquidação e Custódia; STR, Sistema de Transferência de Reservas.

mas LBTR. Para isso, foi estruturado o STR (Sistema de Transferência de Reservas) com reformulação da câmera Selic; (ii) foram adaptados e criados novos sistemas, no âmbito privado, para assegurar que eventuais riscos na compensação e liquidação de operações permanecessem restritos a esse segmento da economia.

A partir disso, surgiram as câmaras privadas de ativos — renda fixa, renda variável, câmbio e derivativos - e câmaras privadas de pagamentos, as quais passaram a operar os sistemas LDL. A figura 3 mostra a inter-relação das instituições financeiras com as câmaras, os prestadores de serviços e o Banco Central, a partir da adoção do novo sistema de pagamentos brasileiro. O Sistema de Transferências de Reservas (STR) passou a ser o centro do processo, organizando e administrando as transferências de recursos entre as contas de reservas bancárias, as contas de liquidação de câmaras e prestadores de serviços de compensação e liquidação e a conta única do Tesouro Nacional. Assim, as transferências interbancárias de fundos são liquidadas 
pelo STR e pelas seguintes câmaras: (i) Câmara Interbancária de Pagamentos (CIP) e (ii) Serviço de Compensação de Cheques e outros Papéis (Compe). Além disso, o sistema da CIP combina características de liquidação LDL e LBTR, enquanto a Compe utiliza liquidação diferida com compensação multilateral de obrigações. ${ }^{12}$

O STR conta ainda com a Selic, que opera com títulos públicos federais e valores mobiliários, com a Companhia Brasileira de Liquidação e Custódia (CBLC), que efetua operações com ações, além de atuar como depositária central da Cetip, e, portanto, responde pela liquidação de títulos privados. Ambos os casos efetuam liquidação diferida com compensação multilateral de obrigações, realizada em D+1, exceto para ações, que é D+3. As operações com derivativos e câmbio interbancário são processadas pela BM\&F, por meio de dois sistemas: a clearing de Derivativos e a clearing de Câmbio, com liquidações em $\mathrm{D}+1$ e $\mathrm{D}+2$, respectivamente. Há também a Câmara Central Clearing de Compensação e Liquidação S.A., que atua no sentido de compensar e liquidar títulos públicos e privados.

\section{IMPACTOS GERADOS PELO NOVO SISTEMA DE PAGAMENTOS BRASILEIRO}

A introdução do novo sistema de pagamentos brasileiro trouxe efeitos relevantes sobre o controle de riscos associados à compensação e à liquidação de pagamentos e ativos no país. Houve inovações no que concerne ao gerenciamento e à operacionalização das contas de reservas bancárias pelos integrantes do sistema. A implantação de sistemas LBTR passou a exigir dos bancos a provisão ou a existência de saldo nas contas em qualquer circunstância. No âmbito do Banco Central, destaca-se a criação do STR, a reestruturação do sistema Selic e a nova modalidade de redesconto de liquidez, o redesconto intradia.

O novo sistema de pagamentos brasileiro em operação requereu das instituições financeiras um nível mais elevado de reservas disponíveis no primeiro momento, como se observa na tabela 3. A proporção das reservas bancárias em relação à base monetária passou de 33,3\% em abril para $36,1 \%$ em maio de 2002. Isso se deveu à adaptação do sistema bancário à exigência de que todas as operações deveriam conter saldo nas contas e 
Tabela 3: Evolução dos meios de pagamento restritos e seus componentes, no Brasil, durante o período 2002-2003

\begin{tabular}{|c|c|c|c|c|c|c|c|}
\hline Período & $\mathrm{BM}^{*}$ & PME \% & RB \% & $\mathrm{M}^{*}{ }^{*}$ & PMPP \% & DV \% & K \\
\hline Jan/02 & 49722 & 65,1 & 34,9 & 74672 & 36,5 & 63,5 & 1,48 \\
\hline Fev & 47891 & 67,0 & 33,0 & 73938 & 36,2 & 63,8 & 1,49 \\
\hline Mar & 48854 & 66,6 & 33,4 & 73215 & 37,2 & 62,8 & 1,49 \\
\hline Abr & 46745 & 66,7 & 33,3 & 74760 & 34,9 & 65,1 & 1,50 \\
\hline Mai & 51513 & 63,9 & 36,1 & 73786 & 36,7 & 63,3 & 1,50 \\
\hline Jun & 50692 & 66,9 & 33,1 & 79666 & 35,6 & 64,4 & 1,55 \\
\hline Jul & 52432 & 66,1 & 33,9 & 82770 & 35,0 & 65,0 & 1,51 \\
\hline Ago & 54985 & 66,2 & 33,8 & 85509 & 36,1 & 63,9 & 1,50 \\
\hline Set & 60769 & 62,2 & 37,8 & 88176 & 35,7 & 64,3 & 1,50 \\
\hline Out & 60640 & 64,6 & 35,4 & 88821 & 37,3 & 62,7 & 1,49 \\
\hline Nov & 60558 & 67,8 & 32,2 & 91946 & 37,8 & 62,2 & 1,49 \\
\hline Dez & 73302 & 68,1 & 31,9 & 102308 & 39,3 & 60,7 & 1,46 \\
\hline Jan/03 & 64370 & 67,8 & 32,2 & 98719 & 40,0 & 60,0 & 1,43 \\
\hline Fev & 67494 & 64,7 & 35,3 & 91911 & 39,8 & 60,2 & 1,43 \\
\hline Mar & 66032 & 60,4 & 39,6 & 89413 & 38,1 & 61,9 & 1,29 \\
\hline Abr & 68229 & 57,2 & 42,8 & 87485 & 38,5 & 61,5 & 1,30 \\
\hline Mai & 65114 & 59,6 & 40,4 & 85089 & 39,1 & 60,9 & 1,29 \\
\hline Jun & 63838 & 60,8 & 39,2 & 85398 & 37,4 & 62,6 & 1,30 \\
\hline Jul & 67841 & 57,8 & 42,2 & 86081 & 38,6 & 61,4 & 1,30 \\
\hline Ago & 58430 & 68,1 & 31,9 & 85746 & 39,5 & 60,5 & 1,33 \\
\hline Set & 56110 & 69,8 & 30,2 & 86147 & 38,1 & 61,9 & 1,46 \\
\hline Out & 57710 & 69,6 & 30,4 & 87243 & 39,0 & 61,0 & 1,47 \\
\hline Nov & 62417 & 68,4 & 31,6 & 90084 & 38,3 & 61,7 & 1,48 \\
\hline Dez & 73219 & 70,2 & 29,8 & 104892 & 39,3 & 60,7 & 1,48 \\
\hline
\end{tabular}

Fonte: Relatório Anual do Banco Central do Brasil (2001, 2002, 2003).

Notas: $\mathrm{BM}=$ Base Monetária; $\mathrm{M1}$ = Meios de Pagamento; PME = Papel-Moeda Emitido; RB = Reservas Bancárias; PMPP = PapelMoeda em poder do público; DV = Depósitos à vista; $\mathrm{K}=$ Multiplicador Monetário.

*Saldos em final do período em R\$ milhões; os percentuais referem-se à participação dos componentes agregados monetários.

seriam contabilizadas pelo seu valor bruto em tempo real. Entretanto, nos meses subseqüentes, nota-se que o comportamento das reservas bancárias retornou aos patamares anteriores à reestruturação. Na realidade, as variações das reservas têm sido sensíveis apenas à elevação da taxa de recolhimento dos depósitos compulsórios. Esse fato também é observado no que se refere à base monetária e M1. As mudanças ocorridas estão muito mais relacionadas às condições da política monetária, questões políticas e crises internacionais do que propriamente à alteração do sistema de pagamentos da economia brasileira. Nota-se ainda que a participação do papel-moeda em poder do público e de depósitos à vista tem se mantido relativamente constante ao longo dos dois anos.

O monitoramento instantâneo das contas de reservas bancárias pelo Banco Central fez com que os bancos participantes do sistema financeiro redobrassem esforços para manter suas contas positivas ao longo do dia. 


\begin{tabular}{|c|c|c|c|c|c|c|c|c|}
\hline \multirow{4}{*}{$\begin{array}{l}\text { Instrumentos } \\
\text { utilizados para } \\
\text { pagamentos }\end{array}$} & \multicolumn{4}{|c|}{ Primeiro semestre de 2001} & \multicolumn{4}{|c|}{ Primeiro semestre de 2003} \\
\hline & \multicolumn{2}{|c|}{ Qtde Doc. } & \multicolumn{2}{|c|}{ Montante } & \multicolumn{2}{|c|}{ Qtde Doc. } & \multicolumn{2}{|c|}{ Montante } \\
\hline & - de $R \$$ & + de $R \$$ & - de $R \$$ & + de $R \$$ & - de $R \$$ & + de $R \$$ & - de $R \$$ & + de $R \$$ \\
\hline & $5 \mathrm{mil}$ & $5 \mathrm{mil}$ & $5 \mathrm{mil}$ & $5 \mathrm{mil}$ & $5 \mathrm{mil}$ & 5 mil & $5 \mathrm{mil}$ & $5 \mathrm{mil}$ \\
\hline Cheque & 98,70 & 1,30 & 30,00 & 70,00 & 98,90 & 1,10 & 55,20 & 44,80 \\
\hline Documentos & 85,20 & 14,80 & 3,00 & 97,00 & 96,10 & 3,90 & 39,80 & 60,20 \\
\hline TED (STR) & & & & & 11,10 & 88,90 & 0,20 & 99,80 \\
\hline
\end{tabular}

Fonte: Banco Central do Brasil (2004), Lima (2002) e Febraban (2004).

Nota: TED/STR = Transferência Eletrônica Disponível / Sistema de Transferência de Reservas.

Para manter em curso as transações efetuadas pelos bancos, o Banco Central passou a exigir depósitos prévios junto às câmaras integrantes do novo sistema. Além disso, a criação da Transferência Eletrônica de Disponível (TED) tem como intuito realizar transferências de grandes valores em tempo real, ou seja, superiores a R $\$ 5$ mil. ${ }^{13}$ Esse fato teria como conseqüência imediata a redução do risco sistêmico do setor financeiro da economia.

A tabela 4 mostra a migração dos instrumentos de pagamento do sistema Compe para o STR, cujo número de cheques com valores maiores do que R $\$$ 5 mil, no decorrer do primeiro semestre de 2001, representava pouco mais de $1 \%$ dos documentos liquidados. No entanto, isso equivalia a um montante de $70 \%$ do total transacionado. Nesse período ainda, a quantidade de DOC acima de $\mathrm{R} \$ 5$ mil representava quase 15\% dos documentos e equivalia a 97\% do total. Já no primeiro semestre de 2003, os valores transferidos pela TED, isto é, acima de $\mathrm{R} \$ 5$ mil, passaram a representar perto de 90,0\%, correspondendo praticamente a $100 \%$ do valor total transacionado. Verifica-se uma queda expressiva no volume de documentos líquidos de 14,8\% para 3,90\% antes e depois da implantação do sistema, respectivamente. Isso vem a confirmar que o novo sistema tende a reduzir gradualmente o risco sistêmico.

O novo sistema de pagamentos brasileiro também impôs mudanças nos segmentos de ações e derivativos. A liquidação das operações desses mercados - que anteriormente era feita na Cetip — passou a ser feita diretamente pelo sistema de transferência de reservas. Para Santos (2002) e Goldfain (2002), a nova versão do SPB eliminou certo tipo de monopólio que vigora- 
va no sistema financeiro nacional. A Cetip respondia pela custódia de títulos de renda fixa privados, a CBLC pelas ações e a Bolsa de Mercadorias e Futuros pelos mercados futuros e derivativos. A implantação do novo sistema permitiu maior flexibilização nas transações e na organização do próprio mercado. Esse sistema teve como implicação também alterações nos procedimentos relativos ao controle e à distribuição do meio circulante e dos conceitos envolvidos no cálculo dos recolhimentos compulsórios.

Em síntese, a reestruturação do sistema de pagamentos, de forma global, apresentou vantagens e desvantagens ao sistema financeiro. No que se refere às vantagens, observa-se: (i) a liquidação plena das ordens de pagamentos; (ii) a redução do tempo decorrido entre o início da transação e sua liquidação final; (iii) a adoção de práticas internacionais, oferecendo maior segurança ao investidor estrangeiro; e (iv) o surgimento de novas oportunidades de negócios para as instituições financeiras. Por outro lado, as desvantagens do novo sistema referem-se ao alto custo de implantação e ao custo adicional de manter reservas bancárias.

\section{CONCLUSÃO E CONSIDERAÇõES FINAIS}

O sistema de pagamentos eficiente é de crucial importância para que o setor financeiro cumpra seu papel de intermediação de recursos entre os agentes econômicos, além de aumentar a liquidez dos ativos transacionados. Desse modo, o desenvolvimento do setor financeiro está intimamente associado aos avanços do sistema de pagamentos, no sentido de oferecer solidez e segurança às transações realizadas na economia.

Os resultados mostram que a maioria dos bancos centrais dos países desenvolvidos que integram o Comitê de Sistemas de Pagamentos e de Liquidações, em particular os dos Estados Unidos, do Japão e do Reino Unido, adotam os sistemas de liquidação pelo valor líquido e sistemas de liquidação pelo valor bruto em tempo real. Esses sistemas também têm sido implantados nas economias em desenvolvimento, como a mexicana e a argentina. Tal fato é uma resposta quanto à necessidade de uma administração mais eficaz dos riscos nos sistemas de pagamentos. Esses sistemas passaram a ser mais vulneráveis em razão do aumento significativo dos fluxos globais de capitais, decorrente de uma progressiva liberalização e inovação dos instrumentos financeiros. 
No que se refere à participação dos meios de pagamento nos produtos das economias, a análise indicou que essa proporção está diretamente relacionada ao desenvolvimento do sistema financeiro de cada país. Em geral, as economias desenvolvidas tendem a apresentar as participações dos meios de pagamento mais elevadas. Nos Estados Unidos, a participação média do M1 no produto gira em torno de 13\%; no Japão, por sua vez, chega a aproximadamente $46 \%$, com tendência de crescimento.

O novo sistema de pagamentos brasileiro, que entrou em operação em 2002, também teve a finalidade de tornar o sistema financeiro mais seguro. O Banco Central, seguindo exemplo dos demais países, adotou os sistemas de liquidação pelo valor bruto em tempo real e instituiu o Sistema de Transferência de Reservas. Essa nova sistemática passou a requerer dos bancos a provisão ou existência de saldo nas contas de reservas bancárias em qualquer circunstância. Em conjunto a isso, o sistema conta com a Transferência Eletrônica Disponível, que tem por objetivo realizar transferências de grandes valores em tempo real. Essas medidas têm como efeito imediato a redução da exposição do sistema financeiro a riscos sistêmicos.

Por último, a reestruturação do sistema de pagamentos brasileiro não trouxe, no período 2002-2004, impactos relevantes sobre o comportamento dos meios de pagamento mais restritos. Entretanto, esse sistema modificou o perfil de utilização dos instrumentos de pagamento no país. Houve um crescimento do uso dos débitos e créditos diretos, dos cartões de crédito e de débito e uma diminuição do uso de cheques, principalmente de grandes valores. Ainda assim, pode-se concluir que o Brasil continua sendo, comparativamente a outros países, um grande usuário de instrumentos de pagamento tradicionais, mas com clara tendência a uma forte expansão dos pagamentos por meios eletrônicos.

\section{NOTAS}

1. Uma abordagem mais completa sobre esse tema pode ser encontrada em Andrezo e Lima (2001), Assaf Neto (1999), Blanchard (1999), Fernardes (2002), Furtuna (1999), Gordon (2002), Hillbrecht (2001), Lopes e Rossetti (2002) e Sachs e Larrain (2000), entre outros.

2. Uma conceituação mais detalhada dos intermediários financeiros pode ser encontrada em Sachs e Larrain (2000: 672), Fernardes (2002), Furtuna (1999), Gordon (2002) e Hillbrecht (2001). 
3. Geralmente, compreende o risco de perda de receitas não realizadas em virtude de contratos não liquidados, pela inadimplência da contraparte (o chamado risco de custo de reposição), e o risco de perda do valor integral da transação (risco de principal).

4. G-10: grupo de países industrializados composto por Alemanha, Bélgica, Canadá, EUA, França, Holanda, Reino Unido, Japão, Suécia e Suíça.

5. Nos mecanismos de Entrega Contra Pagamento, a transferência da custódia dos títulos está atrelada à mensagem de liquidação financeira específica. Já o mecanismo em um sistema de liquidação de moedas estrangeiras assegura que a transferência definitiva de uma moeda ocorre se, e somente se, a transferência da outra moeda também ocorrer.

6. As estruturas de fluxo de mensagens dos sistemas de pagamentos podem ter, além do formato em V e em L , o formato em Y e em T; veja-se BIS (1997: 22).

7. Para um participante individual num sistema LBTR, há quatro possíveis fontes de fundos de liquidez do sistema de pagamentos: (i) os saldos mantidos em conta no Banco Central como depósitos compulsórios, (ii) as transferências de outros bancos, (iii) as concessões de crédito pelo Banco Central e (iv) os empréstimos de outros bancos por meio dos mercados monetários; veja-se BIS (1997).

8. Diferentemente de outros países, na Argentina, a distinção entre os sistemas de alto ou baixo valor se baseia principalmente na duração dos procedimentos interbancários de compensação e liquidação das diferentes transações. Os procedimentos interbancários nos quais a liquidação ocorre no prazo de 24 horas a partir da solicitação da transação são considerados como procedimentos de sistema de alto valor, e os que realizam liquidações após 24 horas a partir da solicitação são considerados de baixo valor.

9. Embora tenham ocorrido avanços no que se refere aos riscos e à segurança nas transações financeiras, novos desenhos para os sistemas de pagamentos vêm sendo discutidos pelos dois países da América Latina.

10. A liquidação em moeda estrangeira fora do Brasil não está no âmbito do Bacen. É realizada com os operadores correspondentes no exterior, normalmente, por meio de clearings como o Chips, em Nova Iorque, o Fedwire do FED para grandes transferências, ou via lançamentos internos, quando se trata de correspondente no exterior comum a dois ou mais bancos brasileiros.

11. A Compe era operada pelo Banco do Brasil S.A. e o Banco Central desbloqueia os cheques transferidos para a conta do favorecido um dia útil após o dia do depósito, quando o limite do cheque for igual ou superior a $\mathrm{R} \$ 300$, debitando o valor da conta do sacado no mesmo dia e creditando o favorecido no dia seguinte. Quando se trata de cheques abaixo desse valor, o prazo para desbloqueio é de dois dias úteis.

12. Para o Bacen (2004), Compensação Multilateral é o procedimento que se caracteriza pela apuração da soma dos resultados bilaterais devedores e credores de cada participante em relação aos demais. O resultado da compensação multilateral também corresponde ao resultado de cada participante em relação à câmara ou ao prestador de serviços de compensação e de liquidação que assuma a posição da parte contratante, para fins de liquidação das obrigações realizadas por seu intermédio. 
13. O limite de $\mathrm{R} \$ 5$ mil para a TED deve-se a simulações realizadas pelo Banco Central, as quais teriam mostrado que as operações financeiras liquidadas por cheques e por DOC acima desse valor poderiam gerar grande risco para o sistema de pagamentos.

\section{REFERÊNCIAS BIBLIOGRÁFICAS}

ANDIMA (2002) Sistema de pagamentos brasileiro. Rio de Janeiro: Associação Nacional das instituições de Mercado Aberto.

ANDREZO, A. F., LIMA, I. S. (2001) Mercado Financeiro: aspectos históricos e conceituais. São Paulo: Pioneira Thomson Learning.

ASSAF NETO, Alexandre (1999) Mercado financeiro. 2. ed. São Paulo: Atlas, p. 322.

BACEN (2004) “A reforma do sistema de pagamentos brasileiro - SPB”. Disponível em http:// www.bcb.gov.br/ Banco Central do Brasil/SPBINTRO. Acesso em 4/6/2004.

BIS (1999) “Sistema de liquidação pelo valor bruto em tempo real”, Bank for International Settlements. Basiléia, p. 40 Disponível em http://www.bis.org/publ/index.htm. Acesso em $22 / 5 / 2004$.

BLANCHARD, O. J. (1999) Macroeconomia: teoria e política econômica. Rio de Janeiro: Campus, p. 623.

BM\&F (2004) “Informações sobre as Clearings de Câmbio e Derivativos”. Bolsa de Mercadoria e Futuro. Disponível em www.bmf.com.br. Acesso em 30/7/2004.

BRITO, A. (2002) "A reestruturação do sistema de pagamentos brasileiro e seus impactos nas instituições financeiras”. Revista Contabilidade \& Finanças. São Paulo: USP, n. 28, p. 6685 , jan./abr.

FERNANDES, A., A. G. (2002) O Brasil e o sistema financeiro nacional. Rio de Janeiro: Qualitymark, p. 545.

FEBRABAN (2004) “Manual para clientes e bancários”. Disponível em http://www.febraban. org.br/Novo - SPB/index.htm. Acesso em 14/9/2004.

FORTUNA, E. (1999) Mercado financeiro: produtos e serviços. 13. ed. Rio de Janeiro: Qualitymark. p. 519.

GOLDFAIN, I. (2002) “Transformações em curso no sistema financeiro”. Março. Disponível em http://www.bcb.gov.br. Acesso em 7/6/2004.

GORDON, R. J. (2002) Macroeconomia. 7. ed. Porto Alegre: Bookman, p. 422.

HILLBRECHT, R. (1999) Economia monetária. São Paulo: Atlas, p. 390.

LOPES, J. C., ROSSETTI, J. P. (2002) Economia monetária. 8. ed. São Paulo: Atlas, p. 470.

SACHS, JEFFREY D., LARRAIN, F. B. (2000) Macroeconomia. São Paulo: Makron Books, p. 945. 